\title{
AS INTELIGÊNCIAS MULTIPLAS EM ALUNOS DE ENGENHARIA CIVIL: UMA PESQUISA EXPLORATÓRIA
}

THE MULTIPLE INTELLIGENCES IN CIVIL ENGINEERING STUDENTS:

AN EXPLORATORY RESEARCH

\section{Recebimento: 01/09/2016- Aceite: 1/10/2016- Publicação: 29/11/2016 Processo de Avaliação: Double Blind Review}

\author{
Orlando Roque Silva ${ }^{1}$ \\ Doutor em Engenharia de Produção \\ Professor do Programa de Mestrado do Centro Universitário das Faculdades \\ Metropolitanas Unidas \\ orlandoroque@uol.com.br
}

\section{Mauro Elias Gebran}

Mestrado Profissional em Administração pela Faculdade Campo Limpo Paulista

(FACCAMP)

mgebran@,faccamp.br

Tiago Barbosa da Silva

Especialista em Docência para o Ensino Superior

Faculdade Campo Limpo Paulista (FACCAMP)

tiago.bsilva@outlook.com

\section{RESUMO}

A profissão do Engenheiro Civil requer além do que se pensa em bons cursos e estudos, ela exige que seus profissionais ajam com toda intensidade de suas inteligências e competências. Este trabalho teve como objetivo analisar o perfil dos alunos do curso de Engenharia Civil de uma faculdade do interior do estado de São Paulo, sendo que seu objetivo específico foi o de identificar as inteligências lógico-matemática e espacial entre eles em seus respectivos semestres. Para tanto elegeu-se a pesquisa de natureza qualitativa e indutiva e de caráter exploratório. Foi aplicado em sala de aula um questionário semiestruturado onde seus respondentes foram os alunos matriculados do primeiro ao décimo semestre durante o segundo semestre de 2015, sendo que desta amostra separou-se aleatoriamente $20 \%$ do seu total. Os resultados mostraram que o perfil desses alunos ainda carece de ser trabalhado já que profissionalmente a exigência recai sobre cálculos e noções de espaços.

PALAVRAS-CHAVE: Inteligências Múltiplas, Competências, Engenharia Civil.

\footnotetext{
${ }^{1}$ Autor para correspondência: UniFMU - Centro Universitário Faculdades Metropolitanas Unidas. Av. Liberdade, 654.CEP 01502 001. São Paulo, SP, Brasil.
} 


\begin{abstract}
The profession of Civil Engineer requires beyond what you think of good courses and studies, it requires its employees to act with all the intensity of their intelligence and skills. This study aimed to analyze the profile of Civil Engineering students of a college in the state of São Paulo, and its specific purpose was to identify the logicalmathematical and spatial intelligences among them in their respective semesters. Therefore chose to research qualitative and inductive nature and exploratory. It was applied in the classroom a semi-structured questionnaire where your respondents were students enrolled from first to tenth semester during the second half of 2015, and this sample was separated randomly $20 \%$ of its total. The results showed that the profile of these students still needs to be worked professionally since the requirement lies with calculations and space notions.
\end{abstract}

KEYWORDS: Multiple Intelligences, Powers, Civil Engineering.

\title{
INTRODUÇÃO
}

Nos últimos anos ocorreu um crescimento considerável pela procura de cursos de engenharias pelos alunos entrantes. Não raramente, a disputa cresce nas mais diversas áreas da Engenharia tanto dos cursos já tradicionais como também dos cursos emergentes advindos da globalização das duas últimas décadas.

No Brasil esse crescimento acompanhou a tendência mundial sendo que as Engenharia Civil, Engenharia de Produção, Engenharia Mecânica, Engenharia Ambiental, Engenharia Clinica e Engenharia Química foram as que mais cresceram. Dentre estas citadas, o curso de Engenharia Civil e o curso de Arquitetura e Urbanismo tiveram maior expressão.

A profissão do Engenheiro Civil exige capacitação adequada e especial, tanto que está regulamentada na Resolução n 218 de 29 de Junho de 1973, adendo do Art. $7^{\circ}$ da Lei $n^{0}$. 5.194/66 que refere-se à atividades profissionais do Engenheiro, do Arquiteto e do Engenheiro Agrônomo. Por este motivo no curso de Engenharia Civil as Instituições de Ensino Superior também estabelecem nos conteúdos programáticos de suas grades de ensino um mergulho profundo nas áreas de formação dessa matéria que podemos classificar como pura "ciências exatas".

O objetivo geral desta pesquisa foi o de analisar o perfil dos alunos do curso de Engenharia Civil de uma faculdade do interior de São Paulo. Sendo que o objetivo específico foi identificar as inteligências lógico-matemática e espacial entre os alunos do curso de engenharia civil e seus respectivos semestres.

A pesquisa foi do tipo qualitativa de natureza indutiva de caráter exploratório. Como delimitação, foi escolhido o Curso de Engenharia Civil, que a partir de Gardner (1994) responderam o inventário de IM com questões semiestruturadas variando-se sua quantidade de nove a onze questões, por grupo de Inteligências, adaptado e organizado 
pelos autores, sendo seus respondentes os alunos do primeiro ao décimo semestre de ambos os sexos e de qualquer idade.

Para esta pesquisa os autores incluíram no IM as informações sobre o perfil de cada aluno, a saber: qual seu semestre no Curso; qual sua idade e sua faixa salarial. O questionário foi aplicado em horário de aula e nas respectivas classes correspondentes à cada semestre e seus alunos.

Após a aplicação dos questionários, os dados foram tratados por meio da análise de conteúdo e organizados em categorias de respostas (Bardin, 2008). Os dados foram tratados em planilhas de Excel obtendo êxito nos resultados alcançados.

\section{OBJETIVOS}

\subsection{Objetivo Geral}

Analisar o perfil dos alunos do curso de engenharia civil de uma faculdade do interior de São Paulo.

\subsection{Objetivos Específicos}

- Verificar a inerência das inteligências múltiplas nos alunos do curso de engenharia civil;

- Identificar a aderência das inteligências lógico-matemática e espacial entre os alunos do curso de engenharia civil em seus respectivos semestres;

- Propor para a IES atividades que desenvolvam os alunos nas inteligências múltiplas que não contemplam seu perfil, voltadas ao curso pesquisado.

\subsection{Problematização}

Pensar e desenvolver as atividades de maneira rápida e com resultado eficaz nem sempre é fácil. De fato, não é fácil para as pessoas que não têm a habilidade necessária para tanto.

Há uma resposta favorável para se concluir esse debate, pois todo ser humano é dotado de inteligências natas ou inatas. As inteligências do ser humano foram estudadas por diversos pesquisadores, porém esta pesquisa se baseará nos achados de Gardner (1994, apud Armstrong, 2001) com o título de "As Oito Inteligências Múltiplas", que descreve-as como: Inteligência Linguística, Inteligências Lógico-Matemática, Inteligência Espacial, Inteligência Corporal-Cinestésica, Inteligência Musical, Inteligência Interpessoal, Inteligência Intrapessoal e Inteligência Naturalista.

Antunes (2000, p. 11) argumenta que a inteligência do ser humano é um produto de uma operação cerebral que permite ao indivíduo resolver problemas e até criar produtos (coisas). Continua dizendo: "Dessa maneira, a inteligência serve para nos tirar de alguns "apertos" sugerindo opções que, em última análise, levam-nos a escolher a melhor solução para um problema".

Nesta pesquisa, a curiosidade era como essas inteligências poderiam ser encontradas nos alunos do curso de engenharia civil.

Levando-se em conta que um Engenheiro Civil deve possuir, entre outras habilidades: ser analítico, ter conhecimentos físicos-matemáticos e avaliar social e 
ambientalmente o impacto de suas atividades, surgiu a ideia de saber, entre os alunos já mencionados, quais inteligências mais se destacam para que possam ser profissionais eficazes.

Então, em vista do conceito de Inteligências e do conceito do perfil do engenheiro civil surge a pergunta que norteia esta pesquisa: Os alunos do Curso de Engenharia Civil, demonstram habilidades com as Inteligências Lógico-Matemática e Espacial mais que as outras Inteligências Múltiplas estudadas por Gardner?

\section{METODOLOGIA}

A partir de Gardner (1994) utilizou-se o inventário das Inteligências Múltiplas, a saber: Inteligência Linguística, Inteligências Lógico-Matemática, Inteligência Espacial, Inteligência Corporal-Cinestésica, Inteligência Musical, Inteligência Interpessoal, Inteligência Intrapessoal e Inteligência Naturalista, com questões semiestruturadas variando-se sua quantidade de nove a onze questões, por grupo de Inteligências, adaptado e organizado pelos autores.

$\mathrm{Na}$ adaptação do questionário, incluiu-se as informações sobre o perfil de cada aluno, a saber: qual seu semestre no Curso; qual sua idade e sua faixa salarial. O questionário foi aplicado em horário de aula e nas respectivas classes correspondentes à cada semestre e seus alunos.

No momento da coleta de dados a IES, contava com 709 alunos matriculados, dentre os quais apenas 666 estavam devidamente em atividade acadêmica.

Para alcançarmos os resultados deste estudo, elegeu-se a pesquisa qualitativa, conforme Godoy (2005).

Quanto a natureza desta pesquisa adotou-se os conceitos de Marconi e Lakatos (2010) trata de uma pesquisa indutiva de caráter exploratório. Como delimitação, foi escolhido o Curso de Engenharia Civil e seus respondentes foram os alunos do primeiro ao décimo semestre de ambos os sexos e de qualquer idade.

Após a aplicação dos questionários, os dados foram tratados por meio da análise de conteúdo e organizados em categorias de respostas (Bardin, 2008). Os dados foram tratados em planilhas de Excel obtendo êxito nos resultados alcançados.

\section{REFERENCIAL TEÓRICO}

\subsection{A Inteligência}

Para estudarmos sobre Inteligências Múltiplas, precisamos entender que Inteligência significa "capacidade de escolha". Todo ser humano tem essa capacidade e pelo que pode-se ler em livros, artigos e reportagens cedidos pelos psicólogos e antropólogos é que por ser a Inteligência algo nato, ela poderá se desenvolver cada vez mais conforme a pessoa busca através de interesses pelos ensinos e aprendizagens contínuos.

De acordo com Antunes (2000) o Pequeno Dicionário Ilustrado Brasileiro da Língua Portuguesa resume Inteligência como "a faculdade de compreender". Por vezes então podemos definir Inteligência como: poder de pensar, ter raciocínio lógico, fazer planejamentos, resolver problemas, compreender as mais diversas ideias, decifrar 
linguagens diferentes, colocar-se no presente, lembrar-se de fatos passados, analisar, aprender, ensinar, etc. Dessa forma pode-se definir como sendo a capacidade de compreender o que acontece à sua volta de forma complexa e profunda.

Ainda Antunes (2000) diz o seguinte:

Analisando de maneira sucinta as raízes biológicas da inteligência, descobrese que ela é produto de uma operação cerebral e permite ao sujeito resolver problemas e, até mesmo, criar produtos que tenham valor específico dentro de uma cultura. Dessa maneira, a inteligência serve para nos tirar de alguns "apertos" sugerindo opções que, em última análise, levem-nos a escolher a melhor solução para um problema qualquer (p. 11).

Antunes (2000, p.12) afirma que não existe uma inteligência geral, e esse mesmo autor explica que:

A inteligência é, pois, um fluxo cerebral que nos leva a escolher a melhor opção para solucionar uma dificuldade e que se completa como uma faculdade para compreender, entre opções, qual a melhor: ela também nos ajuda a resolver problemas ou até mesmo a criar produtos válidos para a cultura que nos envolve (p.12).

O mesmo autor argumenta que a inteligência não constitui um elemento neurológico isolado e independente do ambiente. Pierre Lévy (1993, apud Antunes, 2000)

\subsection{As Oito Inteligências Múltiplas de Gardner}

Haward Gardner, um psicólogo de Harcard, foi o pesquisador do século XX que mais estudou e pesquisou sobre a inteligência do ser humano. Seus achados resultaram nos modelos que hoje se conhece como "Teoria das Inteligências Múltiplas".

Ele argumentou que: "É da máxima importância reconhecer e estimular todas as variadas inteligências humanas e todas as combinações de inteligências. Nós somos tão diferentes, porque possuímos diferentes combinações de inteligências. Se reconhecermos isso, teremos pelo menos uma chance melhor de lidar com muitos dos problemas que enfrentamos neste mundo". GARDNER (1999)

Gardner (1999) questionava a validade de determinar a inteligência de uma pessoa tirando-a de seu meio ambiente natural. Além disso, questionava também a validade de avaliar as pessoas pedindo-lhes para realizar tarefas isoladas que jamais haviam feito antes. O pesquisador sugere então que as inteligências estão mais ligadas com a capacidade do sujeito em resolver problemas assim como, criar produtos nos ambientes com variantes ricos e naturais.

Conforme Armstrong (2001), o conceito de inteligências começou a perder seus segredos tornando-se um conceito funcional que pode operar na vida dos seres humanos das mais variadas maneiras.

Já Antunes (2000) argumenta sobre as Inteligências Múltiplas da seguinte forma:

[...] em neurobiologia sugerem a presença de áreas no cérebro humano que correspondem, pelo menos de maneira aproximada a determinados espaços de cognição, mais ou menos como se um ponto do cérebro representasse um 
setor que abrigasse uma forma específica de competência e de processamento de informações. Embora seja uma tarefa difícil dizer claramente quais são essas áreas, existe o consenso de que possam, cada uma delas, expressar uma forma diferente de inteligência, isto é, de se responsabilizar pela solução específica de problemas ou criação de "produtos" válidos para uma cultura (p. 25).

Os estudos desse autor corroboram com as pesquisas de Howard Gardner quanto às mesmas áreas do cérebro humano que correspondem às Inteligências Múltiplas.

Muito embora pesquisadores mais recentes tentem avaliar as inteligências múltiplas em outros setores organizacionais, os estudos de Gardner primou sobre a avaliação dessas inteligências especificamente de alunos em sala de aula. Quanto a isso Armstrong (2001) afirma que:

\begin{abstract}
Não existe nenhum "megateste" no mercado capaz de oferecer uma avalição completa das Inteligências Múltiplas de seus alunos. Se alguém lhe disser que tem um teste aplicado por computador que em quinze minutos produz um gráfico de barras mostrando os oito "picos" e "vales" de cada aluno de sua turma ou escola, eu sugiro que você não acredite. Isso não significa que a testagem formal não possa oferecer algumas informações sobre as Inteligências de um aluno [...] ela pode dar pistas de várias Inteligências. No entanto, o melhor instrumento isolado para avaliar as Inteligências Múltiplas dos alunos, provavelmente, é o que está facilmente ao alcance de todos nós: a simples observação.
\end{abstract}

Também, a partir de Armstrong (2001) pode-se obter o mapeamento de capacidade dos seres humanos, quando se agrupa essas capacidades em oito categorias ou Inteligências abrangentes para que as avalições se mostrem mais eficazes. Como demonstrado no Quadro 01: 


\begin{tabular}{|c|c|}
\hline AS INTELIGÊNCIAS & SEUS CONCEITOS \\
\hline - Linguística & $\begin{array}{l}\text { - Capacidade de usar as palavras de forma efetiva, quer } \\
\text { oralmente, quer escrevendo. Esta Inteligência inclui a } \\
\text { capacidade de manipular a sintaxe ou a estrutura da linguagem, } \\
\text { a semântica ou os significados da linguagem, e as dimensões } \\
\text { pragmáticas ou os usos práticos da linguagem. }\end{array}$ \\
\hline - Lógico- Matemática & $\begin{array}{l}\text { - Capacidade de usar números de forma efetiva e para } \\
\text { raciocinar bem. Esta Inteligência inclui a sensibilidade a } \\
\text { padrões e relacionamentos lógicos, afirmações e proposições, } \\
\text { funções e outras abstrações relacionadas. }\end{array}$ \\
\hline - Espacial & $\begin{array}{l}\text { - Capacidade de perceber com precisão o mundo visuo-espacial } \\
\text { e de realizar transformações sobre essas percepções. Esta } \\
\text { Inteligência envolve sensibilidade à cor, linha, forma, } \\
\text { configuração e espaço e às relações existentes entre esses } \\
\text { elementos. }\end{array}$ \\
\hline - Corporal-Cinestésica & $\begin{array}{l}\text { - Capacidade e perícia no uso do corpo todo para expressar } \\
\text { ideias e sentimentos e a facilidade no uso das mãos para } \\
\text { produzir ou transformar coisas. }\end{array}$ \\
\hline - Musical & $\begin{array}{l}\text { - Capacidade de perceber discriminar, transformar e expressar } \\
\text { formas musicais. Esta Inteligência inclui sensibilidade ao } \\
\text { ritmo, tom e melodia e timbre de uma peça musical. }\end{array}$ \\
\hline - Interpessoal & $\begin{array}{l}\text { - Capacidade de perceber e fazer distinções no humor, } \\
\text { intensões, motivações e sentimentos das outras pessoas. Esta } \\
\text { Inteligência inclui sensibilidade a expressões faciais, voz e } \\
\text { gestos. Inclui também a sensibilidade de discriminar muitos } \\
\text { tipos diferentes de sinais interpessoais e a capacidade de } \\
\text { responder efetivamente a estes sinais de maneira pragmática. }\end{array}$ \\
\hline - Intrapessoal & $\begin{array}{l}\text { - Capacidade de autoconhecimento e capacidade de agir } \\
\text { adaptativamente com base neste conhecimento. Esta } \\
\text { Inteligência inclui possuir uma imagem precisa de si mesmo, } \\
\text { consciência dos estados de humor, intensões, motivações, } \\
\text { temperamentos e desejos, assim como a capacidade de } \\
\text { autodisciplina, autoentendimento e autoestima. }\end{array}$ \\
\hline - Naturalista & $\begin{array}{l}\text { - Perícia no reconhecimento e classificação das numerosas } \\
\text { espécies (flora e fauna) do meio ambiente do indivíduo. Esta } \\
\text { Inteligência inclui também sensibilidade a outros fenômenos } \\
\text { naturais e, no caso das pessoas que nasceram no meio urbano, a } \\
\text { capacidade de discriminar entre seres inanimados como carros, } \\
\text { tênis e capas de CD's. }\end{array}$ \\
\hline
\end{tabular}

\section{Quadro 01 - A teoria das Inteligências Múltiplas de Gardner}


O Quadro 01 demonstrou as Inteligências Múltiplas e os conceitos aplicados para cada uma delas. A partir dos conceitos descritos o pesquisador poderá identificar nos alunos avaliados qual é de maior destaque.

Para facilitar as avalições quanto as Inteligências Múltiplas de alunos, Armstrong (2001) explica a ideia de Gardner, dizendo:

[...] desenvolver um perfil das Inteligências Múltiplas de uma pessoa não é uma coisa tão simples. Nenhum teste pode determinar precisamente a natureza ou a qualidade das inteligências de uma pessoa. Conforme Howard Gardner salientou repetidamente, os testes padronizados medem apenas uma pequena parte do espectro total das capacidades. A melhor maneira de avaliar as suas Inteligências Múltiplas, portanto, é por meio de um exame realista de seu desempenho nos muitos tipos de tarefas, atividades e experiências associadas a cada inteligência. Em vez de realizar várias tarefas artificiais de aprendizagem, examine retrospectivamente os tipos de experiências de vida real que você teve nestas oito inteligências. O Inventário de IM pode ajudá-lo a fazer isso (p.27).

O Inventário de Inteligências Múltiplas descritas por Armstrong (2001) foi utilizado na integra acrescentando as informações pessoais do perfil de cada respondente.

\subsection{A Engenharia Civil e as Habilidades de Seus Profissionais}

Todas as profissões exigem competências e habilidades apropriadas para que seus profissionais possam exercer suas funções com eficiência e eficácia. Há no mercado de trabalho, profissionais que exercem suas funções naturalmente e ainda aperfeiçoam-se na jornada de seus desempenhos. Outros porém, com um pouco mais de dificuldade se esforçam para conseguir desenvolver suas tarefas profissionais também com tal eficiência e eficácia. A esse fenômeno chamamos de habilidades natas e inatas.

Através da Resolução no 218 de 29 de junho de 1973, o Conselho Federal de Engenharia, Arquitetura e Agronomia resolve, para efeito de fiscalização do exercício profissional correspondente às diferentes modalidades de Engenharia, Arquitetura e Agronomia, em nível superior e em nível médio, atribuir as seguintes atividades: 


\begin{tabular}{|c|c|}
\hline Atividades & Descrição \\
\hline Atividade 01 & Supervisão, coordenação e orientação técnica \\
\hline Atividade 02 & Estudo, planejamento, projeto e especificação \\
\hline Atividade 03 & Estudo de viabilidade técnico-econômica \\
\hline Atividade 04 & Assistência, assessoria e consultoria \\
\hline Atividade 05 & Direção de obra e serviço técnico \\
\hline Atividade 06 & Vistoria, perícia, avaliação, arbitramento, laudo e parecer técnico \\
\hline Atividade 07 & Desempenho de cargo e função técnica \\
\hline Atividade 08 & Ensino, pesquisa, análise, experimentação, ensaio e divulgação técnica, extensão \\
\hline Atividade 09 & Elaboração de orçamento \\
\hline Atividade 10 & Padronização, mensuração e controle de qualidade \\
\hline Atividade 11 & Execução de obras e serviço técnico \\
\hline Atividade 12 & Fiscalização de obra e serviço técnico \\
\hline Atividade 13 & Produção técnica especializada \\
\hline Atividade 14 & Condução de trabalho técnico \\
\hline Atividade 15 & Condução de equipe de instalação, montagem, operação, reparo ou manutenção \\
\hline Atividade 16 & Execução de instalação, montagem e reparo \\
\hline Atividade 17 & Operação e manutenção de equipamento e instalação \\
\hline Atividade 18 & Execução de desempenho técnico \\
\hline
\end{tabular}

Quadro 02 - Atividades descritas para Engenheiros, Arquitetos e Agrônomos

Fonte: Resolução no 218 de 29 de junho de 1973 - Visitado no site

http://www.faccamp.br/site/arq/pdf/graduacao/cursos/bacharelados/engenharia-

geral/RESOLUCAO_218.pdf

Verificou-se no quadro 02 que as atividades atribuídas pelo Conselho Federal de Engenharia, Arquitetura e Agronomia fazem parte do conjunto de competências e habilidades necessárias para o desenvolvimento das atividades propostas em serviços e que podem ser natas ou inatas. 


\section{TRATAMENTO DOS DADOS}

Através da Secretaria Geral, obteve-se informação que em outubro de 2015 o curso de Engenharia Civil contava com 709 alunos matriculados para o segundo semestre de 2015. Porém, a quantidade de alunos ativos para o curso perfazia um total de 666 incluindo-se os períodos Matutino e Noturno. A IES conta com alunos matriculados para os dez semestres para a formação de Engenharia Civil.

Foi aplicado questionário semiestruturado para os alunos do primeiro ao décimo semestre em período de aula.

O Quadro 02 demonstra a situação real de uma amostra de $20 \%$ do total de alunos ativos que se prontificaram a responder o questionário.

\begin{tabular}{|c|c|c|c|}
\hline Semestre & $\begin{array}{l}\text { Quantidade de Alunos } \\
\text { Matriculados }\end{array}$ & $\begin{array}{l}\text { Quantidade de } \\
\text { Respondentes }\end{array}$ & $\begin{array}{c}\text { Média da Faixa } \\
\text { Etária }\end{array}$ \\
\hline $1^{\circ}$ Semestre & 25 & 6 & 26 \\
\hline $2^{\circ}$ Semestre & 120 & 24 & 26 \\
\hline $3^{0}$ Semestre & 35 & 8 & 25 \\
\hline $4^{0}$ Semestre & 131 & 26 & 26 \\
\hline $5^{\circ}$ Semestre & 36 & 8 & 31 \\
\hline $6^{0}$ Semestre & 102 & 20 & 24 \\
\hline $7^{\circ}$ Semestre & 29 & 6 & 24 \\
\hline $8^{0}$ Semestre & 127 & 26 & 28 \\
\hline $9^{\circ}$ Semestre & 44 & 9 & 30 \\
\hline $10^{\circ}$ Semestre & 60 & 12 & 31 \\
\hline
\end{tabular}

Quadro 02 - Dados Extraídos do Questionário aplicado aos Alunos Ativos do Curso de Engenharia Civil

Fonte: Elaborado e organizado pelos Autores. 


\section{ANÁLISE DOS DADOS}

A seguir demonstraremos os resultados encontrados para cada Inteligência Múltipla estudada.

\subsection{Inteligência Linguística}

O Gráfico 01 demonstra o resultado da pesquisa aplicada entre os alunos do Primeiro ao Décimo Semestre.

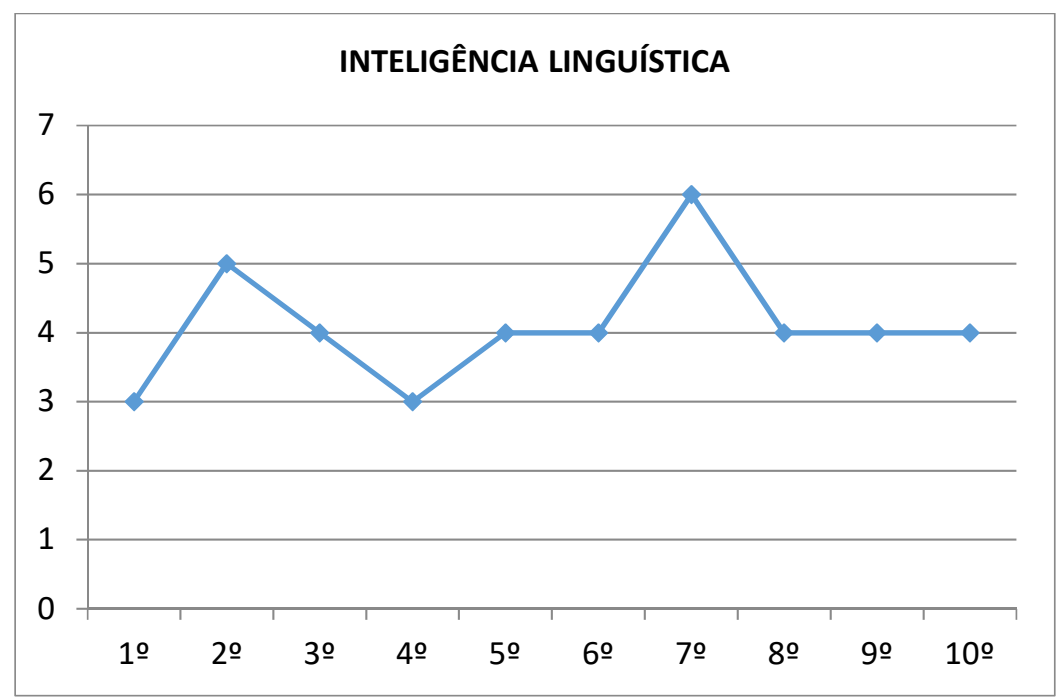

Gráfico 01 - Indicador da Inteligência Linguística

Fonte: Elaborado e Organizado pelos autores a partir dos resultados do Questionário Aplicado

A principal característica da Inteligência Linguística é a capacidade que a pessoa tem para usar as palavras tanto na oratória como na escrita. O Gráfico 01, demonstra que há uma oscilação acentuada entre as médias encontradas entre os alunos do curso pesquisado.

O questionário respondido pelos alunos disponibiliza onze afirmações. Analisando-se as afirmações marcadas, obteve-se a média quatro para esta Inteligência. Então, os resultados foram: o primeiro e o quarto semestres estão abaixo da média, com $27 \%$ das afirmações assinaladas. O terceiro, quinto, sexto, oitavo, nono e décimo estão na média com 36\% das afirmações assinaladas. Contudo, pode-se observar que no segundo e sétimo semestres, encontramos alunos com a IL acima da média, com $45 \%$ e $55 \%$ das afirmações assinaladas respectivamente. 


\subsection{Inteligência Lógico-Matemática}

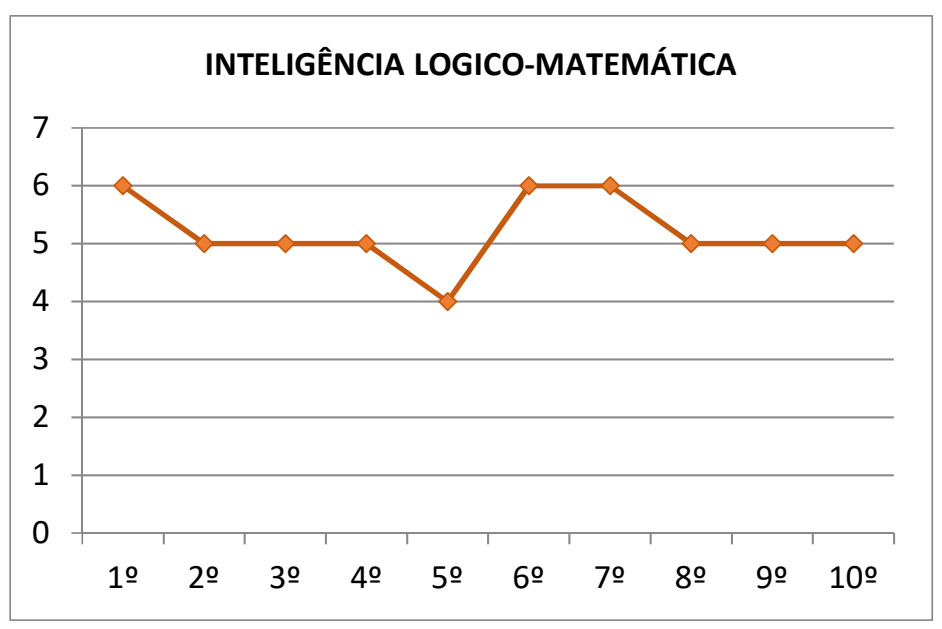

Gráfico 02 - Indicador da Inteligência Lógico-Matemática

Fonte: Elaborado e Organizado pelos autores a partir dos resultados do Questionário Aplicado

O Gráfico 02 demonstra o resultado da pesquisa aplicada entre os alunos do Primeiro ao Décimo Semestre.

A Inteligência Lógico-Matemática, que pelo método indutivo é uma das principais Inteligências a ser encontrada entre os alunos de Engenharia Civil, a caraterística marcante é a pessoa ter capacidade de trabalhar com números de forma efetiva e com raciocínio rápido. Assim, pudemos observar no Gráfico 02 que os resultados permaneceram estáveis entre as médias encontradas durante a contagem e investigação das amostras. Para esta Inteligência o questionário respondido pelos alunos disponibilizou dez afirmações, percebemos a média 5(cinco). Então, temos que apenas o quinto semestre mostrou-se abaixo da média, com $40 \%$ das afirmações assinaladas. $\mathrm{O}$ primeiro, sexto e sétimo semestres tiveram destaque com $60 \%$ das afirmações assinaladas. $\mathrm{O}$ quinto semestre teve seu destaque abaixo da média com apenas $40 \%$ das mesmas afirmações assinaladas. Já os demais semestres mantiveram-se na média com $50 \%$ das afirmações assinaladas.

\subsection{Inteligência Espacial}

O Gráfico 03 demonstra o resultado da pesquisa aplicada entre os alunos do Primeiro ao Décimo Semestre. 


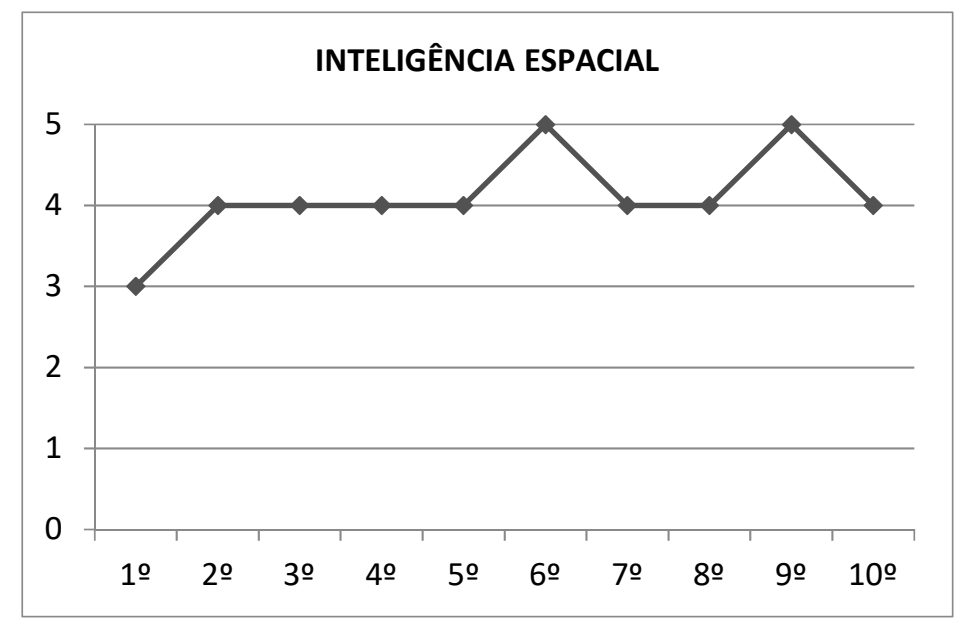

Gráfico 03 - Indicador da Inteligência Espacial

Fonte: Elaborado e Organizado pelos autores a partir dos resultados do Questionário Aplicado

Já, para a Inteligência Espacial, cuja característica principal é a capacidade do indivíduo ter a percepção do mundo visuo-espacial e de poder realizar transformações efetivas sobre essas percepções, pudemos observar no Gráfico 03 resultados surpreendentes, pois a maioria dos alunos, ou seja, $70 \%$ dos alunos estão na média ou acima dela. Para esta Inteligência que contém dez afirmações, a média encontrada foi de 4(quatro) na contagem e investigação das amostras. Então, temos que apenas o primeiro semestre mostrou-se abaixo da média, com $30 \%$ das afirmações assinaladas. O segundo, terceiro, quarto, quinto, sétimo e oitavo semestres mantiveram se na média com $40 \%$ das afirmações assinaladas. Porém, o sexto e o nono semestres se destacaram com $50 \%$ das afirmações assinaladas.

\subsection{Inteligência Corporal-Sinestésica}

O Gráfico 04 demonstra o resultado da pesquisa aplicada entre os alunos do Primeiro ao Décimo Semestre. 


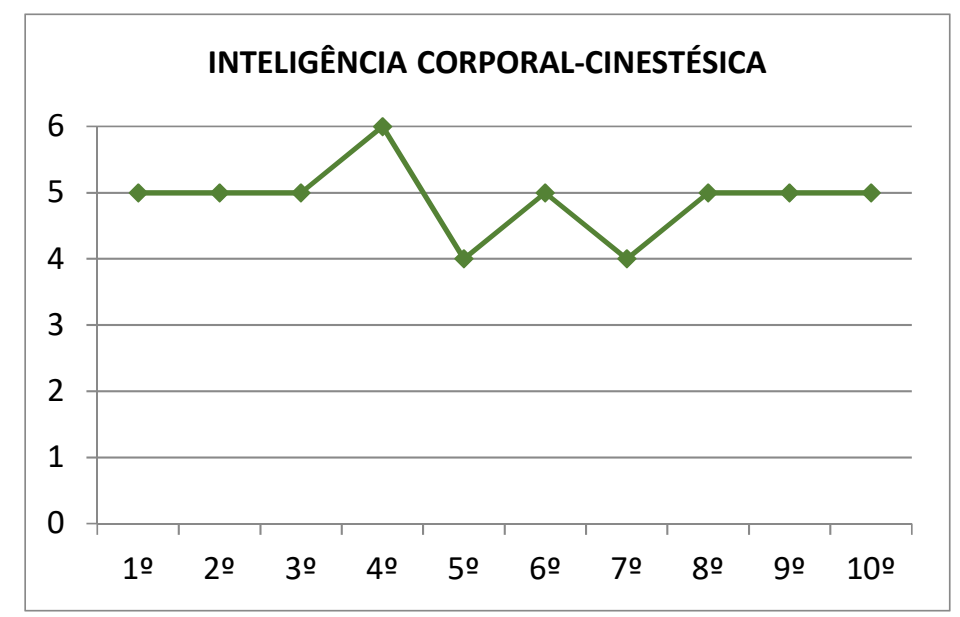

Gráfico 04 - Indicador da Inteligência Corporal-Cinestésica

Fonte: Elaborado e Organizado pelos autores a partir dos resultados do Questionário Aplicado

Como podemos observar no Gráfico 04 os resultados oscilam entre as médias encontradas. Para a Inteligência Corporal-Cinestésica, o IM disponibiliza dez afirmações, que tratando-se como dado indutivo percebemos a média 5. Então, temos que o quinto e o sétimo semestre mostraram-se abaixo da média, com $40 \%$ das afirmações assinaladas. O primeiro, segundo, terceiro, sexto, oitavo, nono e decimo semestre mantiveram se na média com $50 \%$ das afirmações assinaladas. Já o quarto semestre se destacou com $60 \%$ das afirmações assinaladas, obtendo $10 \%$ acima da média nesta pesquisa.

\subsection{Inteligência Musical}

O Gráfico 05 demonstra o resultado da pesquisa aplicada entre os alunos do Primeiro ao Décimo Semestre.

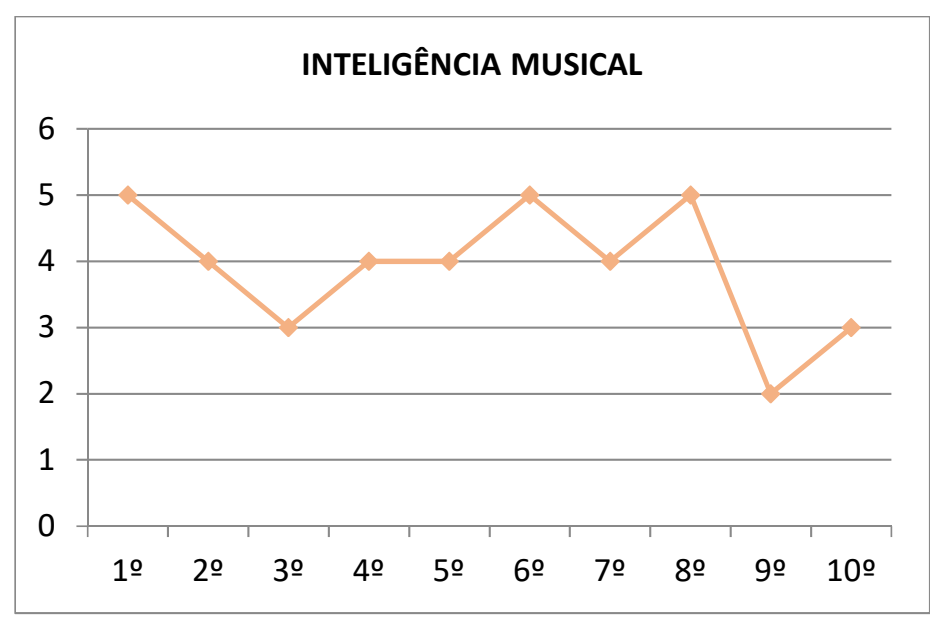

Gráfico 05 - Indicador da Inteligência Musical

Fonte: Elaborado e Organizado pelos autores a partir dos resultados do Questionário Aplicado 
Como podemos observar no Gráfico 05 os resultados oscilam entre as médias encontradas. Para a Inteligência Musical, o IM disponibiliza nove afirmações, percebemos a média 4 na contagem e investigação das amostras. Então, temos que o terceiro e nono semestre mostraram-se abaixo da média, com $33 \%$ e $22 \%$ das afirmações assinaladas respectivamente. $\mathrm{O}$ segundo, quarto, quinto e sétimo, mantiveram se na média com $44 \%$ das afirmações assinaladas. Já o primeiro, sexto e oitavo semestre se destacaram com $56 \%$ das afirmações assinaladas, obtendo $10 \%$ acima da média nesta pesquisa.

\subsection{Inteligência Interpessoal}

O Gráfico 06 demonstra o resultado da pesquisa aplicada entre os alunos do Primeiro ao Décimo Semestre. Como podemos observar no Gráfico 06 os resultados oscilam entre as médias encontradas. Para a Inteligência Interpessoal, o IM disponibiliza dez afirmações, percebemos a média 5 na contagem e investigação das amostras. Então, temos que o terceiro, o sétimo e o oitavo semestre mostraram-se abaixo da média, com $40 \%, 30 \%$ e $40 \%$ das afirmações assinaladas respectivamente. Os demais semestres se mantiveram-se na média com $50 \%$ das afirmações assinaladas.

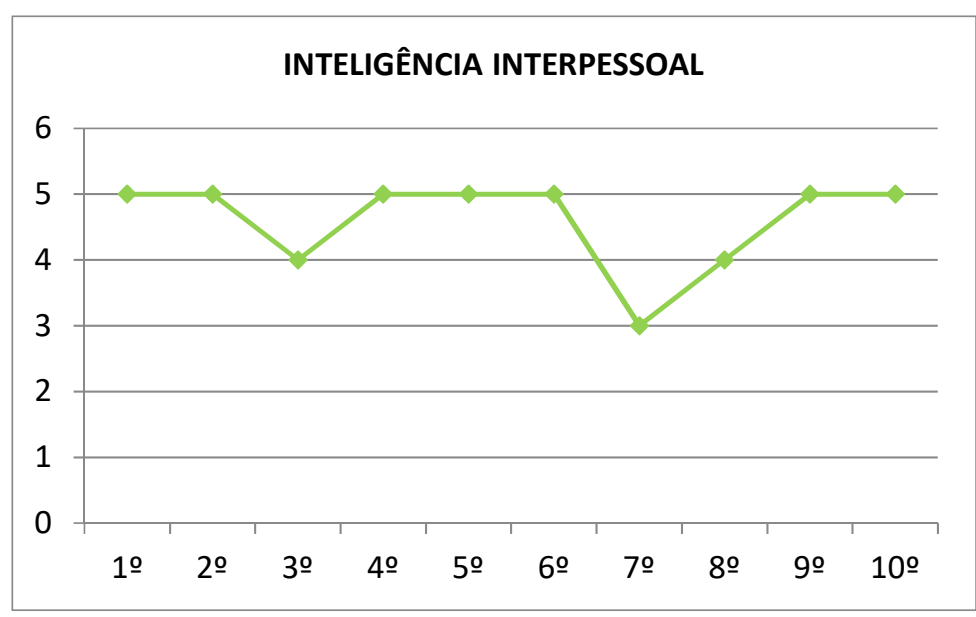

Gráfico 06 - Indicador da Inteligência Interpessoal

Fonte: Elaborado e Organizado pelos autores a partir dos resultados do Questionário Aplicado

\subsection{Inteligência Intrapessoal}

O Gráfico 07 demonstra o resultado da pesquisa aplicada entre os alunos do Primeiro ao Décimo Semestre. 


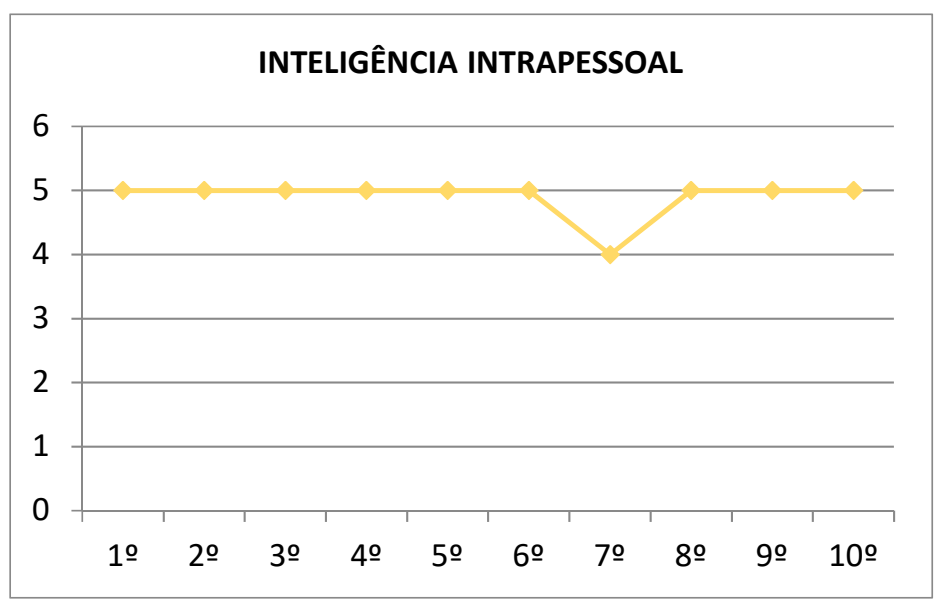

Gráfico 07 - Indicador da Inteligência Intrapessoal

Fonte: Elaborado e Organizado pelos autores a partir dos resultados do Questionário Aplicado

Como podemos observar no Gráfico 07 os resultados se mantem estáveis. Para a Inteligência Intrapessoal, o IM disponibiliza dez afirmações, percebemos a média 5 na contagem e investigação das amostras. Então, temos que apenas o sétimo semestre mostrou-se abaixo da média, com $40 \%$ das afirmações assinaladas. Os demais semestres mantiveram-se na média com $50 \%$ das afirmações assinaladas.

\subsection{Inteligência Naturalista}

O Gráfico 08 demonstra o resultado da pesquisa aplicada entre os alunos do Primeiro ao Décimo Semestre.

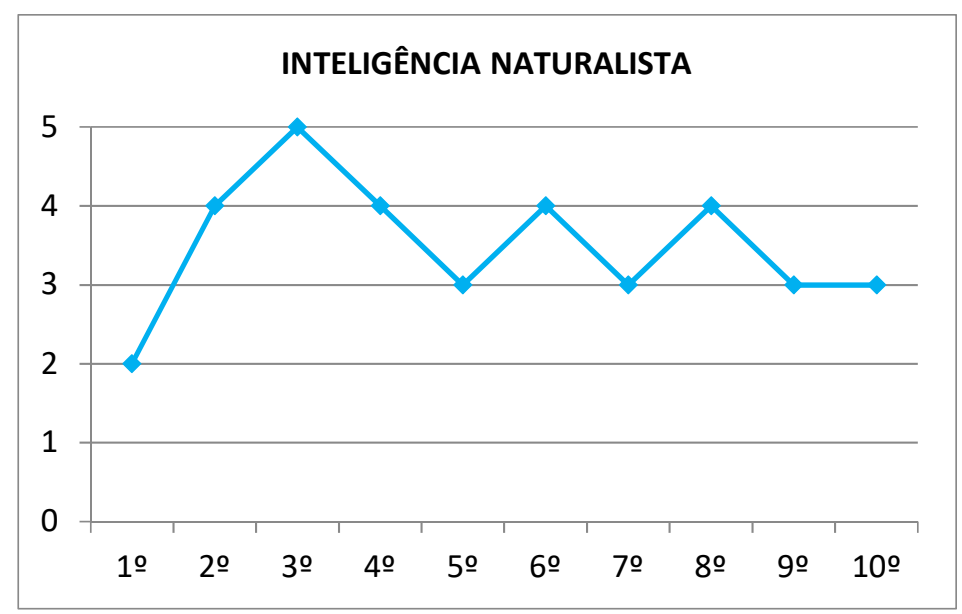

Gráfico 08 - Indicador da Inteligência Naturalista

Fonte: Elaborado e Organizado pelos autores a partir dos resultados do Questionário Aplicado 
Como podemos observar no Gráfico 08 os resultados oscilam entre as médias encontradas. Para a Inteligência Naturalista, o IM disponibiliza dez afirmações, percebemos a média 4 na contagem e investigação das amostras. Então, temos que o primeiro, quinto, sétimo, nono e décimo semestres mostraram-se abaixo da média, com $20 \%, 30 \%, 30 \%, 30 \%$ e $30 \%$ das afirmações assinaladas respectivamente. O segundo, quarto, sexto e oitavo, mantiveram se na média com $40 \%$ das afirmações assinaladas. Já o terceiro semestre se destacou com $50 \%$ das afirmações assinaladas.

\section{RESULTADOS E DISCUSSÕES}

A intenção desta pesquisa é contribuir para que coordenadores e professores do curso de Engenharia Civil construam conteúdos programáticos de acordo com a grade de ensino proposto e ainda desenvolvam atividades curriculares e extracurriculares dentro das necessidades do perfil e tendência do mercado.

Sabendo-se da descrição de atividades do Engenheiro Civil e levando-se em conta os estudos das Inteligências Múltiplas de Gardner (1999), a seguir discutiremos os resultados desta pesquisa em tópicos e sugestões.

\subsection{O Perfil Desejado para Alunos Entrantes no Curso de Engenharia Civil da}

IES

Em pesquisa realizada no site da IES, encontra-se descritas as competências e habilidades técnicas que a Instituição espera dos discentes durante o curso, que são: 


\begin{tabular}{|c|c|}
\hline Competências e Habilidades Técnicas & Descrição \\
\hline Competência & $\begin{array}{l}\text { Aplicar conhecimentos físicos e matemáticos à } \\
\text { Engenharia Civil }\end{array}$ \\
\hline Competência & $\begin{array}{l}\text { Aplicar conhecimentos científicos, tecnológicos e } \\
\text { instrumentais à Engenharia Civil }\end{array}$ \\
\hline Habilidade & $\begin{array}{l}\text { Projetar e conduzir experimentos pertinentes à } \\
\text { Engenharia Civil }\end{array}$ \\
\hline Habilidade & $\begin{array}{l}\text { Interpretar resultados com capacidade crítica, criativa } \\
\text { e responsável }\end{array}$ \\
\hline Competência & $\begin{array}{l}\text { Conceber, projetar e analisar sistemas, produtos e } \\
\text { processos dentro da Engenharia Civil }\end{array}$ \\
\hline Competência & $\begin{array}{l}\text { Planejar, supervisionar, elaborar e coordenar projetos } \\
\text { e serviços de Engenharia Civil }\end{array}$ \\
\hline Habilidade & $\begin{array}{l}\text { Identificar, formular e resolver problemas inerentes à } \\
\text { Engenharia Civil. }\end{array}$ \\
\hline Competência/ Habilidade & $\begin{array}{l}\text { Desenvolver e/ou utilizar novas ferramentas e } \\
\text { técnicas para a aplicação na Engenharia Civil }\end{array}$ \\
\hline Competência & $\begin{array}{l}\text { Supervisionar a operação e a manutenção de sistemas } \\
\text { voltados à Engenharia Civil }\end{array}$ \\
\hline Habilidade & $\begin{array}{l}\text { Avaliar criticamente a operação e manutenção de } \\
\text { sistemas, voltados à Engenharia Civil }\end{array}$ \\
\hline Habilidade & $\begin{array}{l}\text { Comunicar-se eficientemente nas formas escrita, oral } \\
\text { e gráfica }\end{array}$ \\
\hline Habilidade & Atuar em equipes multidisciplinares \\
\hline Habilidade & $\begin{array}{l}\text { Compreender e aplicar a ética e a responsabilidade } \\
\text { profissionais na Engenharia Civil }\end{array}$ \\
\hline Habilidade & $\begin{array}{l}\text { Avaliar social e ambientalmente o impacto das } \\
\text { atividades inerentes à Engenharia Civil }\end{array}$ \\
\hline Habilidade & $\begin{array}{l}\text { Avaliar a viabilidade econômica de projetos de } \\
\text { Engenharia Civil }\end{array}$ \\
\hline Competência & $\begin{array}{l}\text { Assumir a postura de permanente busca de } \\
\text { atualização profissional }\end{array}$ \\
\hline
\end{tabular}

Quadro 04 - Competências e Habilidades Técnicas Desenvolvidas Pelos Discentes Durante o Curso

Fonte: Elaborado e organizado pelos Autores.

O que nos mostra o Quadro 04 são competências e habilidades técnicas que os discentes devem adquirir durante a sua frequência no curso, porém o nosso questionamento é: os alunos que cursam Engenharia Civil são vocacionados em direção a estas competências e habilidades?

A resposta para esse questionamento encontramos na análise dos questionários respondidos pelos alunos. Porém, discutiremos somente as respostas dadas às Inteligências Logico-Matemática e Espacial, devido termos adotado essas Inteligências como as mais influentes no perfil do estudante de Engenharia Civil.

\subsection{Quanto À Inteligência Lógico-Matemática}

Segundo Armstrong (2001) essa inteligência conceitua-se na "Capacidade de usar números de forma efetiva e para raciocinar bem. Esta Inteligência inclui a sensibilidade a padrões e relacionamentos lógicos, afirmações e proposições, funções e outras abstrações relacionadas".

O curso de Engenharia Civil possui uma grade de ensino com base em disciplinas de cálculos como a matemática, física, resistência de materiais, fenômenos 
de transporte o que se pode deduzir que o grau de conhecimento e de facilidade em lidar com cálculos pelos alunos deve ser um nível elevado.

A média estabelecida, indutivamente, para a Inteligência Lógico-Matemática foi de $60 \%$ das afirmações assinaladas. Analisando o Gráfico 02 que demonstrou essa Inteligência, pudemos perceber que o quinto semestre teve seu destaque abaixo da média com apenas 40\% das afirmações assinaladas. Já o segundo, terceiro, quarto, oitavo, nono e décimo semestres mantiveram-se na média com $50 \%$ das afirmações assinaladas. No entanto, o primeiro, sexto e sétimo semestres tiveram destaque com $60 \%$ das afirmações assinaladas.

\subsection{Quanto À Inteligência Espacial}

Para essa Inteligência, Armstrong (2001) conceitua-se como "A capacidade de perceber com precisão o mundo visuo-espacial e de realizar transformações sobre essas percepções". Essa Inteligência envolve sensibilidade à cor, linha, forma, configuração e espaço e às relações existentes entre esses elementos.

Para essa inteligência o Curso de Engenharia Civil também mantém uma grade de ensino com base nas disciplinas de Álgebra Linear, Desenho Técnico e Geometria Analítica que se fundamentam em visão e espaço.

Também para a Inteligência Espacial foi estabelecida uma média, que indutivamente elegeu-se $60 \%$, para que se torne padrão as médias da pesquisa. O Gráfico 03 deste trabalho demonstrou que apenas o primeiro semestre mostrou-se abaixo da média, com 30\% das afirmações assinaladas. O segundo, terceiro, quarto, quinto, sétimo e oitavo semestres mantiveram-se na média com $40 \%$ das afirmações assinaladas. Porém, o sexto e o nono semestres se destacaram com 50\% das afirmações assinaladas. Para esta Inteligência nenhum semestre do Curso de Engenharia Civil atingiu o padrão de $60 \%$ da média, o que pode inferir que tais alunos não possuem habilidades básicas para os estudos das disciplinas citadas.

\section{CONSIDERAÇÕES FINAIS}

Esta pesquisa teve a intenção de estudar o perfil dos alunos de Engenharia Civil da IES. Para isso, foram utilizados os estudos das Oito Inteligências Múltiplas, formalizadas por Gardner (1994) em suas pesquisas sobre as Inteligências dos alunos em sala de aula. Assim, elegemos a Inteligência Lógico-Matemática e a Inteligência Espacial como sendo prioritárias para o desenvolvimento da profissão do engenheiro civil. Indutivamente estabeleceu-se uma média para as mesmas, fixando-se em $60 \%$ das afirmações assinaladas.

Os resultados desta pesquisa mostraram que, para a Inteligência LógicoMatemática, apenas o primeiro, sexto e sétimo semestres atingiram a média estabelecida, demonstrando capacidade de usar os números de forma efetiva e para raciocinar bem, e os demais semestres ficaram abaixo da média estabelecida. 
Quanto à capacidade de perceber com precisão o mundo visuo-espacial e de realizar transformações sobre essas percepções, que é o conceito da Inteligência Espacial, os resultados foram negativos, pois demonstraram que nenhum dos alunos em seus semestres pesquisados atingiram a média estipulada.

Este cenário não representa o que a Instituição espera de seus alunos, uma vez que o perfil desejado para alunos entrantes é que tenham habilidades básicas de matemática e visão de espaço e desenho.

Sendo assim, uma proposta que se faz necessária que é a utilização de testes vocacionais que determinem o nível de aderência dessas duas Inteligências nos alunos entrantes desse curso.

Os resultados mostraram também a urgência no aumento da carga horária para a disciplina de álgebra linear para contribuir no desenvolvimento da Inteligência Espacial.

Incentivar os alunos a participarem das atividades extracurriculares de cálculo básico também pode contribuir para o desenvolvimento dessas duas Inteligências.

Proporcionar atividades de campo (visita técnica) em obras da região de pequeno ou grande porte onde os alunos serão estimulados no desenvolvimento de sua Inteligência Espacial bem como proporcionar essas atividades de campo em empreendimentos da construção civil em condomínios residenciais, industriais ou logísticos. Isso, além do estágio supervisionado que é a obrigatoriedade da grade curricular.

Maior incentivo para participação nas aulas de laboratório, onde o exercício de elaboração de projetos práticos e construção de pesquisas que contribuam para desenvolvimento do aluno trazendo resultados eficazes para o Curso e para a Instituição.

O assunto tratado nesta pesquisa é amplo e merece ainda mais atenção, por isso não é intenção dos autores esgotá-lo, e sim contribuir para que novos pesquisadores e outros interessados possam aprimorá-lo e trazer novas sugestões para formar um perfil adequado dos estudantes e profissionais da Engenharia Civil. 


\section{REFERÊNCIAS}

ANTUNES, Celso. As inteligências múltiplas e seus estímulos. Campinas Papirus 1998. 141 p. ISBN 8530805127.

ARMSTRONG, Thomas. Inteligências múltiplas na sala de aula. 2. ed. Porto Alegre ArtMed 2001. 192 p. ISBN 8573076356.

BERNARDES, Carla Xavier. Inteligências múltiplas: contribuições para o ensinoaprendizagem de língua inglesa. Jundiaí, 2007. 53 p.

GARDNER, Howard. Estruturas da mente: a teoria das inteligências múltiplas. Porto Alegre Artes Médicas 1994. 340 p

MARINS, Lucila Rodrigues. O desenvolvimento da potencialidade dos alunos com base na teoria das inteligências múltiplas. Jundiaí, 2005. 70 p 